\title{
Activity of Nitrogen Containing Carbon Nanotubes in Base Catalyzed Knoevenagel Condensation
}

\author{
S. van Dommele $\cdot$ K. P. de Jong $\cdot$ J. H. Bitter
}

Published online: 28 April 2009

(c) The Author(s) 2009. This article is published with open access at Springerlink.com

\begin{abstract}
The catalytic activity of Nitrogen containing Carbon Nanotubes (NCNT), grown from acetonitrile or pyridine over supported $\mathrm{Fe}-$, Co or Ni catalysts at various conditions, were tested for the base catalyzed Knoevenagel condensation of benzaldehyde and ethylcyanoacetate. All NCNT displayed activity for the reaction with initial turn over frequencies between $9 \times 10^{-3}$ and $5 \times 10^{-2} \mathrm{~s}^{-1}$ which is comparable with to those of activated basic carbons and a rehydrated hydrotalcite. Furthermore, the initial activity per gram of catalyst of NCNT was related to the amount of pyridinic type nitrogen in the NCNT. However, the reaction rate decreased with time on stream which was explained by competitive adsorption of reactant and product. The reaction rate can be described using LangmuirHinshelwood type kinetics including product adsorption.
\end{abstract}

Keywords Carbon nanotubes - Nitrogen doping ·

Base catalysis $\cdot$ Kinetics $\cdot$ Condensation

\section{Introduction}

Base-catalyzed chemical conversions are important industrial processes for the production of drugs, fragrances and chemical intermediates [1,2]. Of special importance are $\mathrm{C}-\mathrm{C}$ coupling reactions such as Aldol condensations, Michael reactions and Knoevenagel condensations [3-5]. Conventionally, almost stoichiometric amounts of homogeneous bases such as hydroxides or methoxides are used for this purpose [6-10]. In such systems several difficult

S. van Dommele $\cdot$ K. P. de Jong · J. H. Bitter $(\bowtie)$

Inorganic Chemistry and Catalysis, University of Utrecht,

Sorbonnelaan 16, 3584 CA Utrecht, The Netherlands

e-mail: J.H.Bitter@uu.nl issues arise of which isolation of the products, the corrosive nature of the reaction mixture and formation of large amounts of waste (salts) are the most important. The amount of waste can be as high as $5-50 \mathrm{~kg}$ for fine chemicals and $25-100 \mathrm{~kg}$ for pharmaceuticals per $\mathrm{kg}$ of desired product [9]. Therefore improved synthesis routes in terms of product purity, yield and minimal waste formation are highly desirable.

One of the major advantages of using heterogeneous base catalysts is the absence of salt formation potentially leading to reusable and environmentally benign processes $[6,7,9,11]$. Examples are (metal) oxides like $\mathrm{MgO}, \mathrm{Al}_{2} \mathrm{O}_{3}$ or $\mathrm{SiO}_{2}$, hydrotalcites, ALPON, alkali doped zeolites and immobilized amines such as aminopropyl silica [12-16].

Beside their potential for electronic applications [17-19] nanostructured carbons, such as carbon nanofibers, have the required physical properties for the use as catalyst (support), such as inertness for various solvents and mechanical strength [20-25]. Nitrogen incorporation in carbon nanotubes (NCNT) is expected to result in base catalysts with the favourable properties of a nanostructured carbon. The basic character of the NCNT originates from the presence of pyridinic like nitrogen $\left(\mathrm{N}_{\mathrm{P}}\right)$, located at the edges of the graphene layers $[26,27]$. Other nitrogen types present are quaternary $\mathrm{N}\left(\mathrm{N}_{\mathrm{Q}}\right)$, pyrrolic $\mathrm{N}\left(\mathrm{N}_{\mathrm{PYR}}\right)$ and oxidized pyridinic $\mathrm{N}\left(\mathrm{N}_{\mathrm{OX}}\right)$ [28-30] however their role in base-catalysis is expected to be limited.

The NCNT used in this study were prepared by chemical vapour deposition of $\mathrm{C}$ - and $\mathrm{N}$-containing precursors (acetonitrile, pyridine) over a supported metal catalyst, viz. Co or Ni supported on $\mathrm{SiO}_{2}$ [31-33]. As test reaction to analyse the NCNT's catalytic activity we chose the Knoevenagel condensation of benzaldehyde (BA) with ethylcyanoacetate (ECA) resulting in ethyl- $\alpha$-cyanocinnamate (ECC) (Scheme 1.) In a preliminary study we showed 
Scheme 1 Knoevenagel condensation; benzaldehyde reacts with ethylcyanoacetate to form ethyl- $\alpha$-cyanocinnamate

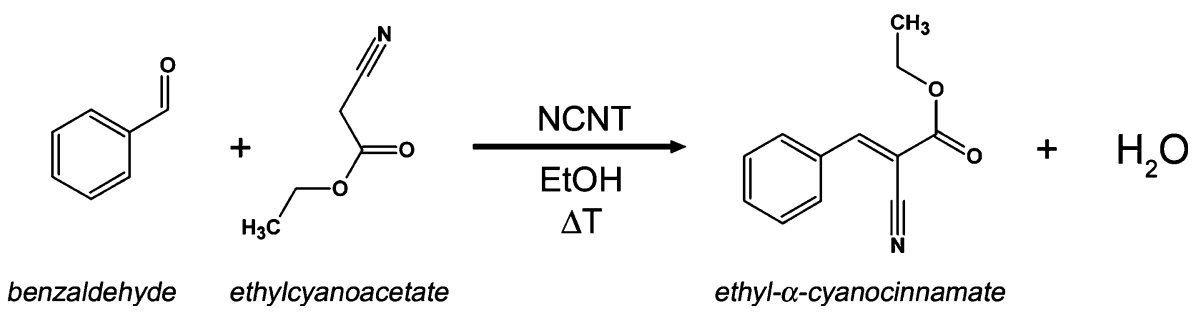

that the pyridinic nitrogen atoms present in the NCNT were responsible for the catalytic activity [27]. Here we report a more detailed study on a kinetic analysis, including product inhibition and mass transfer limitation, of the above mentioned Knoevenagel condensation.

\section{Experimental Section}

\subsection{NCNT Synthesis}

Silica-supported $\mathrm{Ni}$ and Co catalysts with a metal loading of $20 \mathrm{wt} \%$ for the growth of NCNT were prepared via Homogeneous Deposition Precipitation (HDP) using Ni-nitrate or Co-nitrate as described before [34, 35]. For NCNT growth $0.5 \mathrm{~g}$ of the calcined catalyst was loaded into a vertical quartz reactor and heated $\left(5^{\circ} \mathrm{C} \mathrm{min}^{-1}\right)$ in $\mathrm{He}\left(100 \mathrm{~mL} \mathrm{~min}^{-1}\right)$ to $973 \mathrm{~K}$ followed by reduction at that temperature in $20 \% \mathrm{H}_{2} / \mathrm{He}\left(100 \mathrm{~mL} \mathrm{~min}^{-1}\right)$ for $2 \mathrm{~h}$. Next, the temperature of the reactor was adjusted to the desired temperature $\left(5^{\circ} \mathrm{C} \mathrm{min}^{-1}\right)$ for NCNT growth (823-1123 K) while keeping the catalyst in $\mathrm{He}\left(50 \mathrm{~mL} \mathrm{~min}^{-1}\right)$. Subsequently, a $\mathrm{He}$ gas stream saturated at $303 \mathrm{~K}$ with the desired hydrocarbon (acetonitrile or pyridine) was fed to the reactor. After $16 \mathrm{~h}$ the growth reaction was terminated, the reactor was cooled to room temperature in $\mathrm{He}$ and the product, i.e. NCNT together with the growth catalyst, was collected. The product was refluxed in a $1 \mathrm{M}$ potassium hydroxide solution for one hour to remove the silica and, after washing, refluxed in concentrated hydrochloric acid for two hours to remove the exposed metal [36, 37]. Finally, the material was washed with an aqueous ammonia solution to remove any salts formed between the basic sites in the NCNT and the acid. The NCNT were rinsed thoroughly with de-ionized water, dried at $333 \mathrm{~K}$ and stored for further use.

\subsection{Catalysis}

The catalytic activity of the NCNT was tested in the Knoevenagel condensation of benzaldehyde (BA) with ethylcyanoacetate (ECA) to form ethyl- $\alpha$-cyanocinnamate (ECC). The NCNT $(1 \mathrm{~g})$ were heated to $423 \mathrm{~K}$ under vacuum and kept at that temperature for one hour. All further handling was carried out in a nitrogen atmosphere. BA $(0.01 \mathrm{~mol})$ and ECA $(0.01 \mathrm{~mol})$ were dissolved in $50 \mathrm{~mL}$ ethanol (p.a. grade) and any dissolved carbon dioxide was removed using the freeze-thaw method. Subsequently, the reaction mixture was added to the NCNT and the suspension was stirred vigorously and heated to reflux temperature. Samples of the reaction mixture were taken regularly for GC analysis. For reference, a blank reaction of only BA and ECA in $50 \mathrm{~mL}$ ethanol (p.a. grade) was performed; all reported curves are correct for the activity of the blank.

The yield of ECC formed in the Knoevenagel condensation was analyzed with gas chromatography. Aliquots of $1 \mathrm{~mL}$ were taken regularly from the reaction mixture and analyzed with a Chrompack CP9001 GC provided with a Chrompack CP9050 autosampler. Iso-octane was used as an internal standard. A known amount was added to a weighted amount of reaction mixture after removal of the catalyst by filtration.

To investigate the role of diffusion limitation on the catalytic activity the Weisz-Prater number was calculated for each of the NCNT samples for a 1st and 2nd order reaction. The Weisz-Prater number was calculated with Formula 1;

$\Phi=\rho_{\mathrm{p}} \cdot \mathrm{r}_{\mathrm{v}, \mathrm{obs}} \cdot \mathrm{d}_{\mathrm{p}}^{2} \cdot\left(36 \cdot \mathrm{D}_{\mathrm{eff}} \cdot \mathrm{C}_{\mathrm{s}}\right)^{-1} \cdot(1 / 2 \mathrm{n}+1 / 2)<0.15$

The parameters used to calculate the Weisz-Prater number at $353 \mathrm{~K}$ are derived from [38].

For comparison the Knoevenagel condensation was performed using a number of other solid bases. The type of material, pre-treatment and reaction conditions are summarized in Table 1.

The Knoevenagel condensation was performed with these materials in the same manner as the NCNT except for the HT where THF was used as the solvent to prevent the reaction of the HT with ethanol.

\subsection{Characterization}

The N/C atomic ratio in the NCNT was determined by X-ray Photoelectron Spectroscopy (XPS) using a Vacuum Generators XPS system operating with $\mathrm{Al}\left(\mathrm{K}_{\alpha}\right)$ radiation. The raw data were corrected using the binding energy of 
Table 1 Reference materials used in the Knoevenagel condensation, pre-treatment and reaction conditions

\begin{tabular}{lllll}
\hline Solid base & Material & Reference & Pre-treatment & Material amount/solvent \\
\hline HT & Rehydrated hydrotalcite & 39 & Vacuum, 2 h, RT & $0.6 \mathrm{~g} / \mathrm{THF}$ \\
AC-SA-Super & Activated carbon & Norit BV & Vacuum, 2 h, 423 K & $1 \mathrm{~g} / \mathrm{EtOH}$ \\
AC-SX2 & Activated carbon & Norit BV & Vacuum, 2 h, 423 K & $1 \mathrm{~g} / \mathrm{EtOH}$ \\
CNF-OX & Oxidized carbon nanofibers & 38 & Vacuum, $2 \mathrm{~h}, 423 \mathrm{~K}$ & $1 \mathrm{~g} / \mathrm{EtOH}$ \\
CMK-ACN & Nitrogen containing Ordered mesoporous carbon & 40 & Vacuum, $2 \mathrm{~h}, 423 \mathrm{~K}$ & $1 \mathrm{~g} /$ EtOH \\
\hline
\end{tabular}

graphite at $284.4 \mathrm{eV}$. Peak areas were determined after background subtraction using Shirley's method and fitting the spectra with Gaussian curves. The amount of nitrogen incorporated was calculated from the peak areas of the C1s- and N1s peak after correcting for differences in sensitivity using sensitivity factors of 0.540 and 0.972 for $\mathrm{C}$ and $\mathrm{N}$ respectively. The $\mathrm{N} 1 \mathrm{~s}$ peak was deconvoluted into contributions of pyridinic $\mathrm{N}(398.4-399.0 \mathrm{eV})$, pyrrolic $\mathrm{N}$ $(400.0-400.6 \mathrm{eV})$, quaternary $\mathrm{N}(401.1-401.7 \mathrm{eV})$ and $\mathrm{N}-\mathrm{O}$ species $(402.0-405.0 \mathrm{eV})$.

The amount of active sites at the NCNT surface was determined with acid-base titration. First an electrolyte solution was prepared by dissolving $\mathrm{KCl}(7.45 \mathrm{~g})$ in 11 deionized water. A sample of NCNT $(0.1 \mathrm{~g})$ was ground and subsequently dried under reduced pressure at $423 \mathrm{~K}$ for $1-2 \mathrm{~h}$ to remove any adsorbed carbon dioxide. The sample was suspended in the electrolyte solution $(70 \mathrm{~mL})$ and stirred for $24 \mathrm{~h}$ to reach equilibrium. The suspension was then titrated with a hydrochloric acid solution $\left(2 \times 10^{-3} \mathrm{M}\right)$ under continuous stirring and under nitrogen atmosphere. The titrations were performed automatically using a Titralab TIM880. The $\mathrm{pH}$ was recorded as a function of the amount of titrant added. The rate of the addition was limited to a minimum of $0.2 \mathrm{ml} \mathrm{min}^{-1}$ and a maximum of $0.8 \mathrm{~mL} \mathrm{~min}^{-1}$ and in such a way that the $\mathrm{pH}$ changes per second were in the interval 0.01-0.05.

The proton uptake by the NCNT as function of suspension $\mathrm{pH}$ was calculated using Formula 1 [39]:

$\mathrm{N}=\mathrm{V}_{0} \mathrm{C}_{0}+\mathrm{V}_{\mathrm{a}} \mathrm{C}_{\mathrm{a}}-\left(\mathrm{V}_{0}+\mathrm{V}_{\mathrm{a}}\right) \cdot 10^{-\mathrm{pH}}$

Where $\mathrm{N}$ is the amount of protons absorbed by the NCNT in mol, $\mathrm{V}_{0}$ and $\mathrm{V}_{\mathrm{a}}$ represent respectively the volume of the suspension at start of the titration and the volume of acid added in liters, $\mathrm{C}_{0}$ and $\mathrm{C}_{\mathrm{a}}$ are respectively the concentration of protons in the suspension at start of the titration and concentration of the acid in mol $\mathrm{l}^{-1}$.

The proton uptake was plotted as function of $\mathrm{pH}$ and the obtained curves were deconvoluted with Gaussian curves of which the position of the peak's maximum corresponds to the $\mathrm{pK}_{\mathrm{a}}$ value of the conjugated acid of a particular basic site on the NCNT surface. The $\mathrm{pK}_{\mathrm{a}}$ value of a certain basic site was determined by taking the derivative of the titration curve ( $\mathrm{pH}$ as function of titrant addition) and locating the maxima of the derivative curve. With the maximum the equivalence point could be found which was then used to find the corresponding $\mathrm{pKa}$ value using the following relationship:

$\mathrm{pK}_{\mathrm{a}}=\mathrm{pH}$ at $\mathrm{V}=1 / 2 \mathrm{~V}_{\mathrm{eq}}$

The pKa values were used as starting points to fit the proton uptake curve by varying the peak FWHM and position of the maximum within a set limit $(\Delta \mathrm{pH}=1)$.

Titration curves of pure nitrogen containing organic compounds were taken as reference. Pyridine $(0.01 \mathrm{mmol})$, 4-methylpyridine $(0.01 \mathrm{mmol})$, quinoline $(0.01 \mathrm{mmol})$, benzylamine $(0.004 \mathrm{mmol})$, piperidine $(0.04 \mathrm{mmol})$ or triethylamine $(0.04 \mathrm{mmol})$ were dissolved in $70 \mathrm{~mL}$ of the electrolyte solution. Subsequently these solutions were titrated with hydrochloric acid under continuous stirring and nitrogen flow.

\section{Results}

Figure 1 displays both medium and high resolution TEM micrographs of a typical NCNT sample. Uniform NCNT were observed with an average tube diameter of $25 \mathrm{~nm}$. The medium magnification micrograph displayed a significant contrast between the centre and edge of the material suggesting tube morphology and an on-top view (examples indicated with arrows) further proved that the material comprised hollow tubes. High resolution TEM (Fig. 1, inset) showed that the prepared materials consisted of multiwall tubes with an average graphene sheet spacing of $3.4 \AA$. Some physico-chemical properties of the NCNT that have been used for catalytic testing are given in Table 2. NCNT samples are denoted according to the growth catalyst, growth temperature and $\mathrm{C} / \mathrm{N}$ source. For example, NCNT grown over a cobalt catalyst at $823 \mathrm{~K}$ from acetonitrile has been denoted as Co823ACN. All NCNT materials were mesoporous without micropores.

The N/C atomic ratios were determined with XPS (Table 2) and varied between 0.05 and 0.10 which equals respectively 3.7 and $7.9 \mathrm{mmol} \mathrm{N}$ per gram NCNT. The amount seemed to decrease with increasing growth temperature for a given growth catalyst and $\mathrm{C} / \mathrm{N}$ source. 


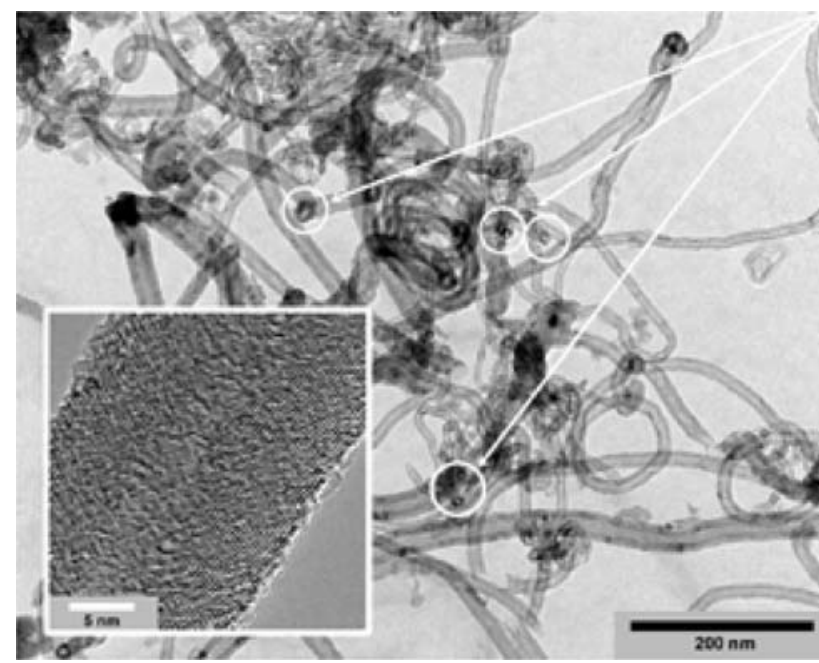

Fig. 1 TEM images of Co923ACN. Arrows indicate the on-top view of the tubes. The inset is an HRTEM image of an NCNT showing parallel graphene layers

Further analysis of the N1s spectrum revealed the presence of different types of nitrogen species in the NCNT graphene sheets, i.e., pyridynic, quaternary, pyrrolic and $\mathrm{N}$-oxides. The fraction of pyridinic nitrogen, $\mathrm{N}_{\mathrm{P}} / \mathrm{N}_{\mathrm{T}}$ in Table 2 where $\mathrm{N}_{\mathrm{T}}$ denotes pyridinic-, pyrrolic- and oxidic $\mathrm{N}$ species, varies between 0.35 and 0.65 and is an indication of the relative amount of basic $\mathrm{N}$.
The amount of basic sites at the surface of the samples was calculated from titration data and was in the range $0.037-0.074 \mathrm{mmol} \mathrm{g}^{-1}$ for the NCNT. Here we determined the total amount of surface sites by deconvolution of proton uptake curves which were derived from titration curves. This technique provides more detailed information about the $\mathrm{pK}_{\mathrm{a}}$ distribution of the accessible sites than can obtained from titration curves alone as was done before [27]. The site density of the NCNT is about an order of magnitude lower compared to the site density of AC-SAsuper samples and, although acidic, the site density of $\mathrm{CNF}_{\mathrm{OX}}$.

In Table 2 the results of the catalytic testing of all samples, corrected for blank activity, have been compiled. The activity of the blank is shown in Fig. 2 as well; all reported activities are corrected for the blank activity. All NCNT displayed activity for the Knoevenagel condensation of BA and ECA. Figure 2 displays some typical catalytic results of NCNT in which the yield of ECC was plotted as a function of time. As can be seen in this figure, most of the conversion occurred in the first half hour. After that the curve levels off and little increase of the ECC yield is observed. From Fig. 2 it can also be concluded that a high initial rate (Table 2) does not necessarily lead to a high ECC yield after prolonged time. For example, the yield after 4 hours obtained with Ni823ACN, which had an initial rate of $6.6 \mathrm{mmol} \mathrm{g}_{\text {cat }}^{-1} \mathrm{~h}^{-1}$, is similar to the yield

Table 2 Physico-chemical properties of solid bases

\begin{tabular}{|c|c|c|c|c|c|c|c|c|}
\hline Sample & $\begin{array}{l}\mathrm{N} / \mathrm{C}^{\mathrm{a}} \\
\text { (at/at) }\end{array}$ & $\mathrm{N}_{\mathrm{P}} / \mathrm{N}_{\mathrm{T}}$ & $\begin{array}{l}\text { BET surface } \\
\left(\mathrm{m}^{2} \mathrm{~g}^{-1}\right)\end{array}$ & $\begin{array}{l}\text { Mesopore vol } \\
\left(\mathrm{mmol} \mathrm{g}^{-1}\right)\end{array}$ & $\begin{array}{l}\text { Pore diameter } \\
(\mathrm{nm})\end{array}$ & $\begin{array}{l}\text { Active sites } \\
\left(\mathrm{mmol} \mathrm{g}^{-1}\right)\end{array}$ & $\begin{array}{l}\text { TOF } \\
\left(\times 10^{-2} \mathrm{~s}^{-1}\right)\end{array}$ & $\begin{array}{l}\text { Initial activity } \\
\left(\mathrm{mmol} \mathrm{g}_{\mathrm{cat}}^{-1} \mathrm{~h}^{-1}\right)\end{array}$ \\
\hline Co823ACN & 0.10 & 0.65 & 147 & 0.57 & 16 & 0.074 & 5.3 & 14 \\
\hline Co923ACN & 0.06 & 0.56 & 132 & 0.67 & 20 & 0.068 & 2.0 & 4.8 \\
\hline Co1023ACN & 0.05 & 0.51 & 106 & 0.49 & 17 & 0.037 & 2.3 & 3.0 \\
\hline Co1023PYR & 0.10 & 0.55 & 28 & 0.34 & 8 & 0.051 & 1.5 & 2.8 \\
\hline Ni823ACN & 0.06 & 0.66 & 173 & 0.40 & 8 & 0.065 & 2.8 & 6.6 \\
\hline Ni1023ACN & 0.05 & 0.35 & 148 & 0.52 & 14 & 0.057 & 0.9 & 1.8 \\
\hline CMK-ACN & 0.09 & 0.42 & - & - & - & 0.248 & 1.1 & 9.9 \\
\hline $\mathrm{CNF}_{\mathrm{OX}}$ & - & - & 186 & 0.36 & 11 & $0.430^{\mathrm{d}}$ & 0.8 & 1.2 \\
\hline AC-SX2 & - & - & 841 & $0.33\left(+0.27^{\mathrm{g}}\right)$ & - & 0.117 & 1.1 & 4.6 \\
\hline AC-SA-Super & - & - & - & - & - & 1.26 & 2.2 & 10 \\
\hline $\mathrm{HT}^{\mathrm{e}}$ & - & - & - & - & - & $0.160^{f}$ & 4.4 & 25 \\
\hline
\end{tabular}

Reaction conditions: $10 \mathrm{mmol}$ ECA, $10 \mathrm{mmol} \mathrm{BA,} 50 \mathrm{~mL}$ EtOH, $353 \mathrm{~K}$

${ }^{a}$ XPS data

b At surface (titration)

${ }^{c}$ Determined from yield vs time plot

d Acidic sites

e THF used as solvent

${ }^{\mathrm{f}}$ Determined with $\mathrm{CO}_{2}$ adsorption

g Micropore volume 

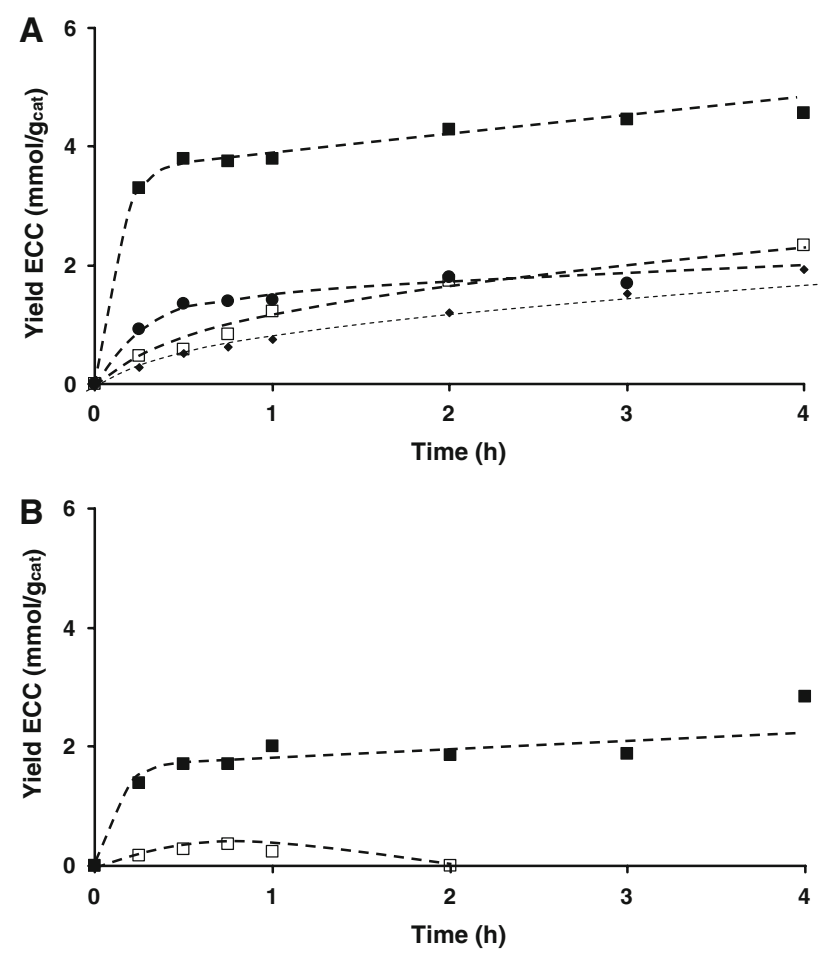

Fig. 2 Knoevenagel condensation with Co grown NCNT (a) and Ni grown NCNT (b) at $823 \mathrm{~K}(\mathbf{\square}), 923 \mathrm{~K}(\bullet)$ and $1023 \mathrm{~K}(\square)$; blank activity $(\bullet)$

obtained with Co1023ACN, which had an initial rate of $3.0 \mathrm{mmol} \mathrm{g}_{\text {cat }}^{-1} \mathrm{~h}^{-1}$.

To get an impression of the reusability of the catalysts, Co823ACN was after the first test experiment filtered off, washed with ethanol, pre-treated as before and used for a second run. The activity of that run (data not shown) was comparable to that of the first one indicating that irreversible deactivation was limited.

The catalytic activity of the NCNT was compared with other solid bases. In Fig. 3 the yield of ECC as function of reaction time is displayed for AC-SX2, AC-SA-super, CMKACN and HT. Also the activity of oxidized Carbon Nanofibers $\left(\mathrm{CNF}_{\mathrm{OX}}\right)$ has been added for comparison. As was observed with the NCNT the conversion of reactants to ECC occurred in the first half hour after which the yield did not increase significantly. The yield of ECC obtained with the HT was rather high, $8.5 \mathrm{mmol} \mathrm{g}_{\mathrm{cat}}^{-1}$. The yield obtained with AC-SA-Super, $4.5 \mathrm{mmol} \mathrm{g}_{\text {cat }}^{-1}$, was comparable to that obtained with one of the NCNT. However, as can be seen in Table 2 the site density on AC-SA-Super is an order of magnitude higher than that of the NCNT. Thus when the activity per site of the catalysts is compared the performance of the activated carbon is rather poor. Furthermore, the yield over AC-SA-Super decreased after 1 hour which suggests that absorption of the product or secondary reactions might occur. The same was observed for AC-SX2.

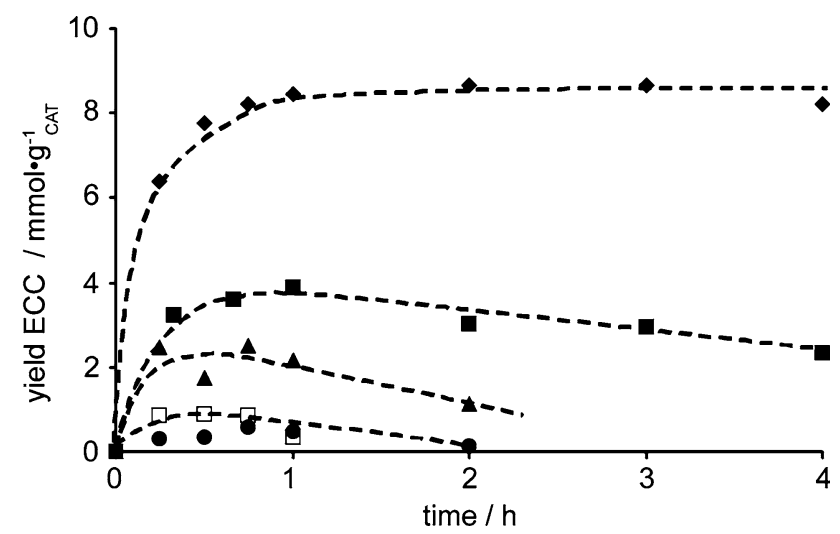

Fig. 3 Yield of ECC plotted as function of reaction time for the Knoevenagel condensation with HT $(\bullet)$, AC-SA-super (ם), AC-SX2 $(\bullet)$, CMKACN $(\boldsymbol{\Delta})$ and $\mathrm{CNF}_{\mathrm{OX}}(\square)$

The acidic $\mathrm{CNF}_{\mathrm{Ox}}$ hardly displayed any activity with an ECC yield of $0.6 \mathrm{mmol} \mathrm{g} \mathrm{g}_{\text {cat }}^{-1}$.

To investigate the possibility of internal diffusion limitation the Weisz-Prater number was calculated for reactants and product for all NCNT samples. The parameters used and the results have been compiled in Table 3 .

As can be seen there were no internal diffusion limitations for any sample in case of a 1st order reaction. If the reaction was 2 nd order only slight diffusion limitations occurred in ECC with the Co823ACN sample.

\section{Discussion}

Figure 2 shows that reactant conversions between $10 \%$ and $50 \%$ to ECC were obtained within the first hour after which little increase in yield was observed. It should be noted that ECC was the only product observed in all experiments. However the final yield is different for all samples even though the reactions conditions were the same in all experiments. Therefore the yield is not limited by the thermodynamic equilibrium of the reaction. Thus we conclude that the active sites are deactivated by the adsorption of (one of) the products. Therefore, we evaluate the catalytic activity of the materials by its initial reaction rate.

The amount of basic N, as determined with acid base titration, is approximately related to the NCNT's initial activity in the Knoevenagel condensation as displayed in Fig. 4. An increase in the number of $\mathrm{N}$ groups leads to an increase in the initial activity.

However, this increase could be caused by any of the basic $\mathrm{N}$ types, amine or pyridinic $\mathrm{N}$. Therefore the possibility that the increase in initial activity is related to the increase of a specific $\mathrm{N}$ type was investigated. For each sample of NCNT the total number of surface $\mathrm{N}$ groups was determined by titration. Then the ratio $\mathrm{N}_{\text {type }} / \mathrm{N}_{\mathrm{T}}$ was 
Table 3 Weisz-Prater numbers $(\Phi)$ for BA, ECA and ECC for the Knoevenagel condensation at $353 \mathrm{~K}$

\begin{tabular}{|c|c|c|c|c|c|c|c|c|c|c|c|c|}
\hline \multirow{2}{*}{$\begin{array}{l}\text { Sample } \\
\text { Reaction order (n) }\end{array}$} & \multicolumn{2}{|c|}{ Co823ACN } & \multicolumn{2}{|c|}{ Co923ACN } & \multicolumn{2}{|c|}{ Co1023ACN } & \multicolumn{2}{|c|}{ Co1023PYR } & \multicolumn{2}{|c|}{ Ni823ACN } & \multicolumn{2}{|c|}{ Ni1023ACN } \\
\hline & 1 & 2 & 1 & 2 & 1 & 2 & 1 & 2 & 1 & 2 & 1 & 2 \\
\hline$\Phi_{\mathrm{BA}}$ & 0.06 & 0.08 & 0.02 & 0.03 & 0.01 & 0.02 & 0.01 & 0.02 & 0.03 & 0.04 & 0.01 & 0.01 \\
\hline$\Phi_{\mathrm{ECA}}$ & 0.06 & 0.09 & 0.02 & 0.03 & 0.01 & 0.02 & 0.01 & 0.02 & 0.03 & 0.04 & 0.01 & 0.01 \\
\hline$\Phi_{\mathrm{ECC}}$ & 0.14 & 0.22 & 0.05 & 0.07 & 0.03 & 0.05 & 0.03 & 0.04 & 0.07 & 0.10 & 0.02 & 0.03 \\
\hline
\end{tabular}

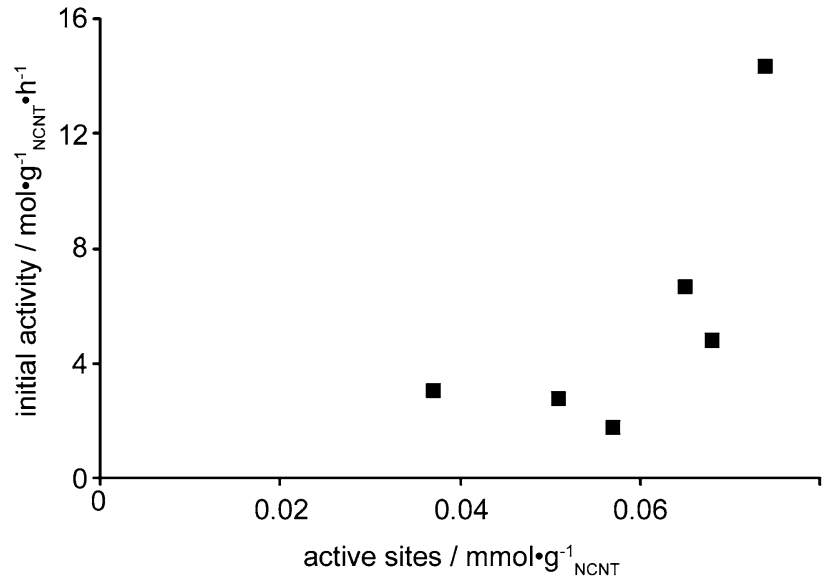

Fig. 4 Relation between the amount of active N sites in NCNT and the initial activity in the Knoevenagel condensation

determined for each of the $\mathrm{N}$ types, i.e. amine $\mathrm{N}$, pyridinic $\mathrm{N}$ and oxidized $\mathrm{N}$, from XPS data where $\mathrm{N}_{\mathrm{T}}$ is the sum of all the mentioned $\mathrm{N}$ types. This ratio was then taken to estimate the number of surface groups of a specific $\mathrm{N}$ type and used as correction factor for Fig. 4. Please note that it was assumed that the ratio of each $\mathrm{N}$ type determined with XPS was constant throughout the whole NCNT. It turned out that the initial activity in the Knoevenagel condensation increased with increasing amount of $\mathrm{N}_{P}$ (Fig. 5), which indicated that this type of nitrogen is (part of) the active site for the reaction. No relation could be found between the other nitrogen species and activity.

To investigate the order of the reaction in Fig. 6 the concentration of BA as function of reaction time is plotted. As can be seen from this figure the conversion of BA is initially rapid and then decreases as can be expected for a batch reactor. The experimental data were compared with a 2nd order rate model, thus assuming that the $\mathrm{C}-\mathrm{C}$ bond formation is the rate determining step. It should be noted that if proton abstraction is the rate determining step, a first order equation would be appropriate [40]. However, the data could not be fitted with a second order rate equation as is illustrated in Fig. 6. As can be seen in Fig. 6 the fit matches the experimental data only at start for Co823ACN and Co923ACN but not beyond half an hour. Only a good fit is observed with Co1023ACN. A mismatch between

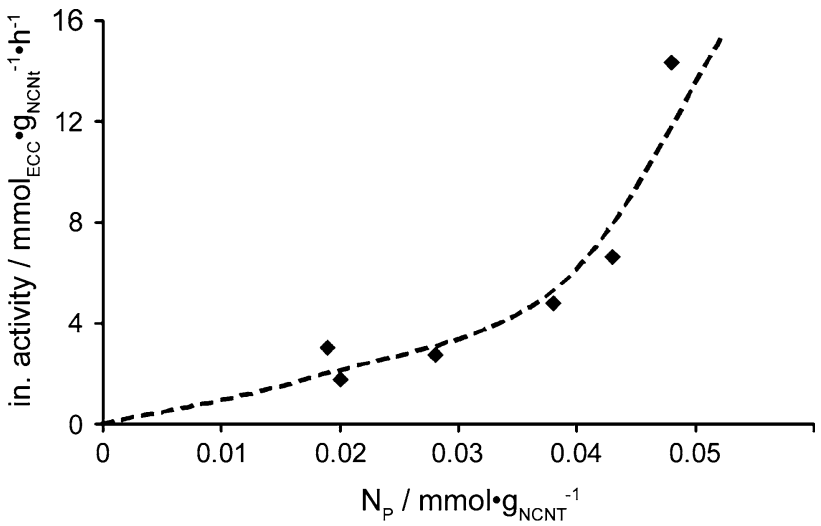

Fig. 5 Relation of pyridinic nitrogen and initial activity [adapted from 27]

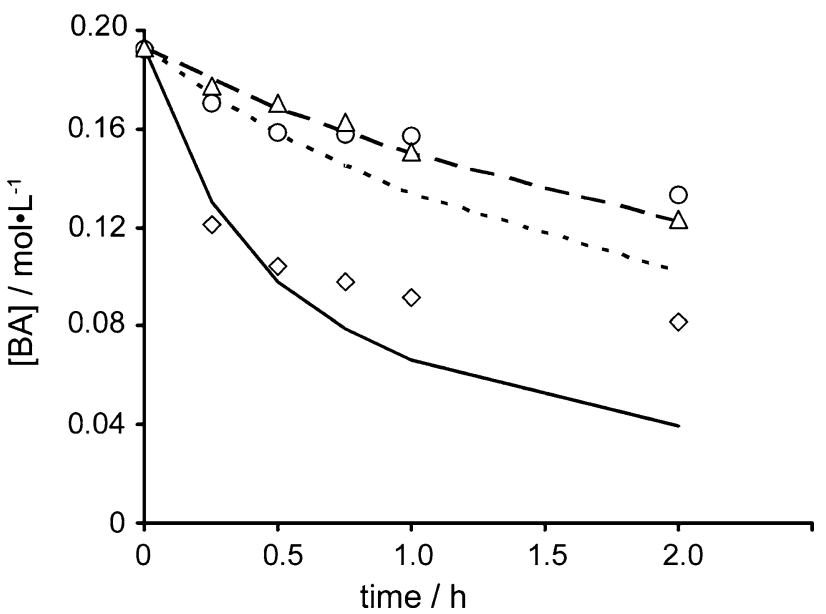

Fig. 6 BA conversion as function of reaction time by Co823ACN $(\diamond)$ and fit (solid line), Co923ACN $(\Delta)$ and fit (dotted line), Co1023ACN $(\bigcirc)$ and fit (dashed line)

experimental data and the rate model was also observed with the other NCNT.

As can be concluded from Fig. 6 the predicted conversion is much higher than is achieved in reality. This may indicate that active sites are deactivated over time as more BA and ECA have reacted and more ECC is formed. This might be explained by inhibition of the active sites by reactants or products, in the latter case either ECC or water. Since the concentration of reactants is relatively high at the 
start of the reaction and the activity of the catalyst decreases as more product is formed, the latter option seems more plausible.

Langmuir-Hinshelwood type kinetics including product inhibition would be needed for an improved model. Here we used the simplified expression:

$\mathrm{r}=(\mathrm{k}[\mathrm{BA}][\mathrm{ECA}]) \cdot\left(1+\mathrm{K}_{\mathrm{c}}[\mathrm{ECC}]\right)^{-1}$

with the assumption of a single site and product inhibition. The reactant and product concentration can be written in terms of conversion ( $\mathrm{x}$ ) and since equimolar amounts BA and ECA are used the following expressions are derived:

$[\mathrm{BA}]=[\mathrm{BA}]_{0} \cdot(1-\mathrm{x})$

$[\mathrm{ECA}]=[\mathrm{BA}]=[\mathrm{BA}]_{0} \cdot(1-\mathrm{x})$

$[\mathrm{ECC}]=[\mathrm{BA}]_{0} \cdot \mathrm{x}$

where $[\mathrm{BA}]_{0}$ is the BA concentration at start of the reaction. Equation 3 can be written as a differential equation:

$[\mathrm{BA}]_{0} \mathrm{dx} / \mathrm{dt}=\left(\mathrm{k}[\mathrm{BA}]_{0}^{2} \cdot(1-\mathrm{x})^{2}\right) \cdot\left(1+\mathrm{K}_{\mathrm{c}}[\mathrm{BA}]_{0} \cdot \mathrm{x}\right)^{-1}$

By solving the integral and using Eqs. 5-7 we arrive at an expression for the concentration of [BA] as function of time with variables $\mathrm{k}$ and $\mathrm{K}_{\mathrm{c}}$ :

$$
\begin{aligned}
{[\mathrm{BA}]=} & \left(\mathrm{K}_{\mathrm{c}}[\mathrm{BA}]_{0}+1\right) \\
& \cdot\left(\mathrm{k} \cdot \mathrm{t}+[\mathrm{BA}]_{0}^{-1}-\mathrm{K}_{\mathrm{c}} \cdot\{\ln (1-\mathrm{x})-1\}\right)^{-1}
\end{aligned}
$$

The results of fitting the experimental data with a Langmuir-Hinshelwood type equation are shown in Fig. 7. As can be seen from this figure the experimental data can be described fairly accurately with the Langmuir-Hinshelwood model. The corresponding $\mathrm{k}, \mathrm{K}_{\mathrm{c}}$ and correlation coefficients are tabulated in Table 4.

From the correlation coefficients in Table 4 it can be concluded that the rate model agrees well with the experimental data and that the Knoevenagel condensation with NCNT follow Langmuir-Hinshelwood type kinetics. As predicted by Eq. 4 the reaction rate decreases as more
Table $4 \mathrm{k}, \mathrm{K}_{\mathrm{c}}$ and $\mathrm{R}^{2}$ values of NCNT for the observed data and the Langmuir-Hinshelwood rate model

\begin{tabular}{lccl}
\hline Sample & $\mathrm{k}\left(\mathrm{L} \mathrm{mol}^{-1} \mathrm{~h}^{-1}\right)$ & $\mathrm{K}_{\mathrm{c}}\left(\mathrm{L} \mathrm{mol}^{-1}\right)$ & $\mathrm{R}^{2}$ \\
\hline Co823ACN & 15 & 50 & 0.992 \\
Co923ACN & 7 & 150 & 0.998 \\
Co1023ACN & 2 & 10 & 0.996 \\
Co1023PYR & 3 & 30 & 0.999 \\
Ni823ACN & 10 & 100 & 0.997 \\
Ni1023ACN & 4 & 40 & 0.990 \\
\hline
\end{tabular}

product, i.e. ECC, is formed which means that competitive adsorption occurs between reactants and products. The calculated k-values showed a quadratic dependency with the amount of pyridinic $\mathrm{N}$ in the NCNT. Therefore, the kvalue can be regarded as being composed of the real $\mathrm{k}$ value and the concentration of pyridinic $\mathrm{N}$ :

$\mathrm{k}=\mathrm{k}_{\mathrm{real}} \cdot\left[\mathrm{N}_{\mathrm{P}}\right]^{\alpha}$

with $\left[\mathrm{N}_{\mathrm{P}}\right]$ the concentration of pyridinic $\mathrm{N}$ and $\alpha$ the reaction order. Since a quadratic relationship exists between $\left[\mathrm{N}_{\mathrm{P}}\right]$ and $\mathrm{k}, \alpha$ should be 2 . By plotting $\mathrm{k}$ as function of $\left[\mathrm{N}_{\mathrm{p}}\right]$ (Fig. 8) and calculating the coefficients of the quadratic fit the value of $\mathrm{k}_{\text {real }}$ was determined to be $5500 \mathrm{~L}^{3} \mathrm{~mol}^{-3} \mathrm{~h}^{-1}$. No relationship between $\mathrm{k}_{\mathrm{c}}$ and $\left[\mathrm{N}_{\mathrm{P}}\right]$ was observed. The second order relationship of $k$ and $\left[\mathrm{N}_{\mathrm{P}}\right]$ suggests a dual site mechanism for the NCNT catalyzed knoevenagel condensation.

The activities of reference materials i.e. activated carbons, hydrotalcite and oxidized CNF, were rather diverse. Relatively high yields of ECC were obtained within one hour with the HT and AC-SA-Super. However, the activity of the latter per active site of the material is rather low (Table 2). The decline in ECC yield with the latter after one hour may be explained by adsorption of product or consecutive reactions. Since no other product besides ECC was observed the first explanation is more plausible especially when it is taken into account that the AC materials were designed as adsorbents for organic molecules. Since the used activated carbons (AC materials) are microporous it likely that the condensation reaction is diffusion limited.
Fig. 7 Experimental BA conversion as function of reaction time fit with a Langmuir-Hinshelwood kinetic model. a Co823ACN $(\diamond)$, Co923ACN $(\diamond)$ and Co1023ACN $(\Delta)$. b Ni823ACN $(\boldsymbol{\square})$, Ni1023ACN $(\bigcirc)$ and Co1023PYR ( $\square)$
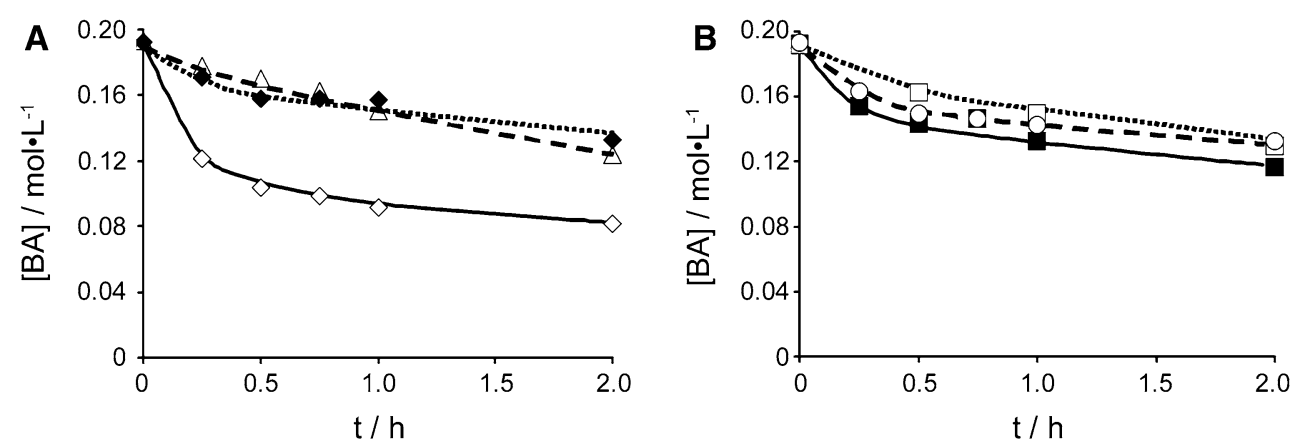


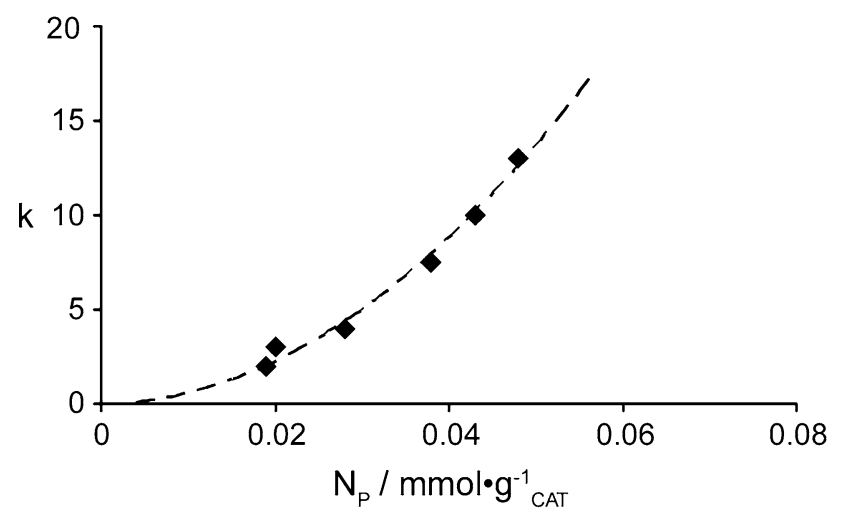

Fig. 8 Relationship between the calculated $\mathrm{k}$ values and the pyridinic $\mathrm{N}$ concentration at the NCNT surface

This further proves that NCNT being mesoporous materials are very suitable for the Knoevenagel condensation if site inhibition can be prevented.

In Fig. 9 a comparison of activities in the Knoevenagel condensation of ECA and BA with different solid bases is displayed. It should be noted that the catalytic data from the literature were obtained at a variety of conditions. Therefore only the order of magnitudes of activities can be compared. The initial activities per gram of NCNT are comparable with some other mildly basic materials [41-44] like fluoro- and hydroxy appatites and aluminophosphate oxynitrides. The higher activities observed with the other types of solid bases may be caused by the number or accessibility of the active site. The highest activities were observed with alkaline exchanged zeolites which had active sites with $\mathrm{pK}_{\mathrm{a}}$ values between 10 and 13. A strong base is not necessarily an advantage since side reactions might occur as well which lead to low product

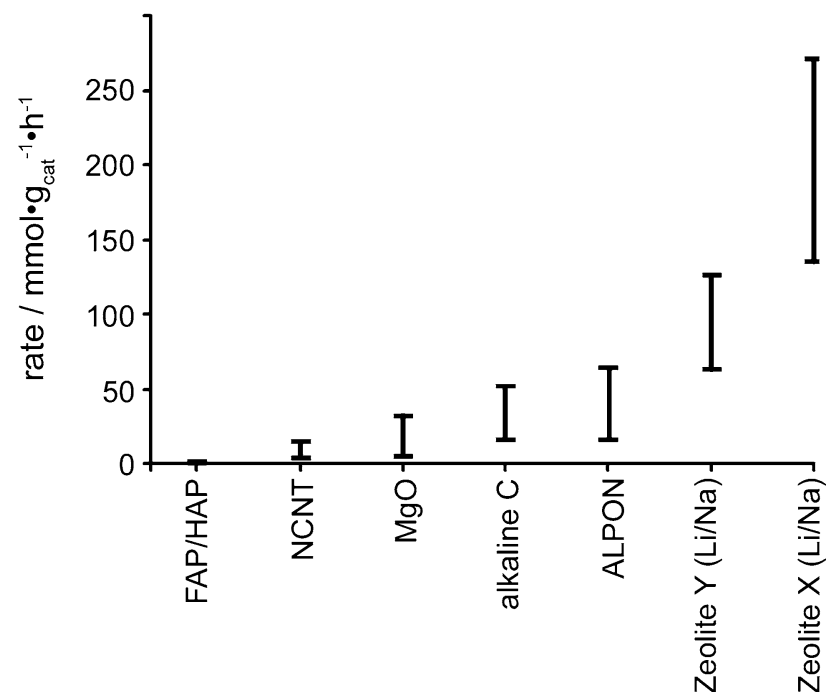

Fig. 9 Activities of solid bases in the Knoevenagel condensation of ECA and BA concentration. NCNT prove to be efficient catalysts for condensation reactions which require mild solid bases. Further study about the incorporation and accessibility of nitrogen at the CNT surface may enhance their catalytic performance.

\section{Conclusions}

We succeeded in preparing a new solid base catalyst that consists of nitrogen-containing CNT. The activity of these materials seems to be determined by the concentration of pyridinic nitrogen present in the catalyst. The observed deactivation of the catalysts was explained by inhibition of the active sites by the formed products. The reaction rate could be described by a Langmuir-Hinshelwood type kinetic model. Calculations showed that the mesoporous NCNT did not suffer from diffusion limitation which is an advantage of these materials over existing microporous basic materials.

Acknowledgments The financial support of the Dutch Science Foundations (NWO) within the "Jonge Chemici" scheme is (project number 700.50.520) gratefully acknowledged.

Open Access This article is distributed under the terms of the Creative Commons Attribution Noncommercial License which permits any noncommercial use, distribution, and reproduction in any medium, provided the original author(s) and source are credited.

\section{References}

1. Kelly GJ, King F, Kett M (2002) Green Chem 4:392-399

2. Tanabe K, Hölderich WF (1999) Appl Catal A Gen 181:399-434

3. Weitkamp J, Hunger M, Rymsa U (2001) Micropor Mesopor Mat 48:255-270

4. Sheldon RA (2000) Pure Appl Chem 72(7):1233-1246

5. Zapf A, Beller M (2002) Top Catal 19(1):101-109

6. King F, Kelly GJ (2002) Catal Today 73:75-81

7. Blaser H-U (2000) Catal Today 60:161-165

8. Poliakoff M, Fitzpatrick JM, Farren TR, Anastas PT (2002) Science 297:807-810

9. Sheldon RA, Molec J (1996) Catal A 107:75-83

10. Kelly GJ, King F, Kett M (2002) Green Chem 4:392-399

11. Winter F, Koot V, van Dillen AJ, Geus JW, de Jong KP (2005) J Catal 236:91-100

12. Ono Y (2003) J Catal 216:406-415

13. Hattori H (2001) Appl Catal A 222:247-259

14. Tanabe K, Hölderich WF (1999) Appl Catal A 181:399-434

15. Clark JH, Macquarrie DJ (1997) Org Process Res Dev 1(2):149_ 162

16. Ono Y, Baba T (1997) Catal Today 38:321-337

17. Baughman RH, Zakhidov AA, de eer WA (2002) Science 297:787-792

18. Avouris P (2002) Chem Phys 281:429-445

19. Kreupl F, Graham AP, Duesberg GS, SteinHögl W, Liebau M, Unger E, Hönlein W (2002) Microelectron Eng 64:399-408

20. Patent application, PCT/NL2005/000274 
21. van der Lee MK, van Dillen AJ, Geus JW, de Jong KP, Bitter JH (2006) Carbon 44:629-637

22. de Jong KP, Geus JW (2000) Catal Rev-Sci Eng 42(4):481-510

23. Serp P, Corrias M, Kalck P (2003) Appl Catal A Gen 253:337358

24. Bitter JH, van der Lee MK, Slotboom AGT, van Dillen AJ, de Jong KP (2003) Cat Let 89(1-2):139-142

25. Czerw R, Terrones M, Charlier JC, Blasé X, Foley B, Kamalakaran R, Grobert N, Terrones H, Tekleab D, Ajayan PM, Blau W, Rühle M, Carroll DL (2001) Nano Lett 1(9):457-460

26. Burg P, Frydrych P, Cagniant D, Nanse G, Bimer J, Jankowska A (2002) Carbon 40:1521-1531

27. van Dommele S, de Jong KP, Bitter JH (2006) Chem Commun 4859-4861

28. Raymundo-Piñero E, Cazorla-Amorós D, Linares-Solano A, Find J, Wild U, Schlögl R (2002) Carbon 40:597-608

29. Pels JR, Kapteijn F, Moulijn JA, Zhu Q, Thomas KM (1995) Carbon 33(11):1641-1653

30. Kapteijn F, Moulijn JA, Matzner S, Boehm HP (1999) Carbon 37:1143-1150

31. Tang C, Bando Y, Goldberg D, Xu F (2004) Carbon 42:26252633

32. Nath M, Satishkumar BC, Govindaraj A, Vinod CP, Rao CNR (2000) Chem Phys Lett 322:333-340
33. van Dommele S, Romero-Izquirdo A, Brydson R, de Jong KP, Bitter JH (2008) Carbon 46:138-148

34. Bezemer GL, Radstake PB, Koot V, van Dillen AJ, Geus JW, de Jong KP (2006) J Catal 237:291

35. van der Lee MK, van Dillen AJ, Bitter JH, de Jong KP (2005) J Am Chem Soc 127:13573

36. Toebes ML, Bitter JH, van Dillen AJ, de Jong KP (2002) Catal Today 76(1):33-42

37. Toebes ML, van Heeswijk JMP, Bitter JH, van Dillen AJ, de Jong KP (2004) Carbon 42(2):307-315

38. Poling BE, Prausnitz JM, O'Connell JP (2000) The properties of gases and liquids, 5th edn. McGRaw-Hill professional, NY

39. Tantavichet N, Pritzker MD, Burns CM (2001) J Appl Polym Sci 81:1493-1497

40. Zhang X, Lai ESM, Martin-Aranda R, Yeung KL (2004) Appl Catal A Gen 261:109-118

41. de D. López-González J, López-Peinado A, Martin-Aranda RM, Rojas-Cervantes ML (1993) Carbon 31(8):1231-1236

42. Corma A, Fornés V, Martin-Aranda RM, García H, Primo J (1990) Appl Catal 59:237-248

43. Elazarifi N, Ezzamarty A, Leglise J, de Ménorval L-C, Moreau C (2004) Appl Catal A Gen 267:235-240

44. Massinon A, Odriozola JA, Bastians Ph, Conanec R, Marchand R, Laurent Y, Grange P (1996) Appl Catal A Gen 137:9-23 